\title{
Effects of Rhizobium Inoculation on Nitrogen Fixation and Growth of Leguminous Green Manure Crop Hairy Vetch (Vicia villosa Roth)
}

Takashi Sato

Additional information is available at the end of the chapter

http://dx.doi.org/10.5772/56992

\section{Introduction}

A green manure crop is used primarily as a soil amendment and a nutrient source for subsequent crops [1]. Legumes have been utilized as biofertilizer in agriculture, because legumes can fix atmospheric dinitrogen $\left(\mathrm{N}_{2}\right)$ and accumulate a large amount of nitrogen in their organs. Accordingly, incorporating of a leguminous green manure crop provides a large amount of nitrogen and carbon source to the soils for subsequent crops. There are many leguminous green manure crops and they have been utilized all over the world [2,3]. Table 1 shows dry weight and nitrogen accumulation of leguminous green manure crops. Legumes including clover, vetch and field pea are cultivated as winter cover crops $[4,5,6]$. They are sometimes planted together with winter cereals such as oats, rye or wheat. Legumes such as cowpea, sesbania, crotalaria or velvet beans may be grown as summer green manure crops to add nitrogen as well as organic matter to the soils $[7,8,9,10]$. Chinese milk vetch (Renge in Japanese) and so on have been cultivated mainly southwest area in Japan, which locate in a warm climate zone $[12,13]$.

Hairy vetch [Vicia villosa Roth] is a leguminous cover crop and used for nutrient management as green manure and weeding in southwest area of Japan. Vetches (plants of the genus Vicia) are distributed throughout the temperate zones. There are many species of vetch, and they are important for agriculture. The species in commercial use, including hairy vetch, are all native to Europe or western Asia. Hairy vetch is a winter annual plant, and some hairy vetch cultivars can grow over winter even in north area of Japan. Recently, hairy vetch is used for increasing soil fertility and improvement of soil structures in an upland field converted from paddy field (Fig. 1). 


\begin{tabular}{|c|c|c|}
\hline Legumes & $\begin{array}{l}\text { Dry weight } \\
\left.(\mathrm{t} \mathrm{ha})^{-1}\right)\end{array}$ & $\begin{array}{l}\text { N accumulation } \\
\left(\mathrm{kg} \mathrm{ha}^{-1}\right)\end{array}$ \\
\hline Soybean [Glycine max (L.) Merr.] & $2.8 \sim 5.8$ & $31 \sim 174$ \\
\hline Sunn hemp [Crotalaria juncea] & $0.9 \sim 11.1$ & 23 279 \\
\hline Siratro [Macroptilium atropurpureum] & $2.4 \sim 5.5$ & $62 \sim 178$ \\
\hline Velvet bean [Mucuna pruriens] & $1.7 \sim 9.3$ & $53 \sim 183$ \\
\hline Sesbania [Sesbania rostrata] & $3.2 \sim 4.6$ & 71 88 \\
\hline Mung bean [Vigna radiata] & $1.1 \sim 5.5$ & $26 \sim 88$ \\
\hline Cowpea [Vigna unguiculata] & $0.6 \sim 8.5$ & $15 \sim 154$ \\
\hline Alfalfa [Medicago sativa] & $0.5 \sim 5.7$ & $21 \sim 174$ \\
\hline Barrel medic [Medicago truncatula] & $1.0 \sim 4.5$ & 37 131 \\
\hline Field pea [Pisum sativum L.] & $3.2 \sim 7.6$ & $107 \sim 230$ \\
\hline Crimson clover [Trifolium incarnatum L.] & $1.4 \sim 7.3$ & $35 \sim 200$ \\
\hline Red clover [Trifolium pratense L.] & $0.3 \sim 3.7$ & $13 \sim 115$ \\
\hline White clover [Trifolium repens L.] & $0.6 \sim 25$ & $17 \sim 592$ \\
\hline Chinese milk vetch [Astragalus sinicus L.] & $3.4 \sim 4.9$ & $101 \sim 158$ \\
\hline Hairy vetch [Vicia villosa Roth] & $1.5 \sim 10.0$ & $58 \sim 257$ \\
\hline
\end{tabular}

Table 1. Dry weight and nitrogen accumulation of leguminous green manure crops.
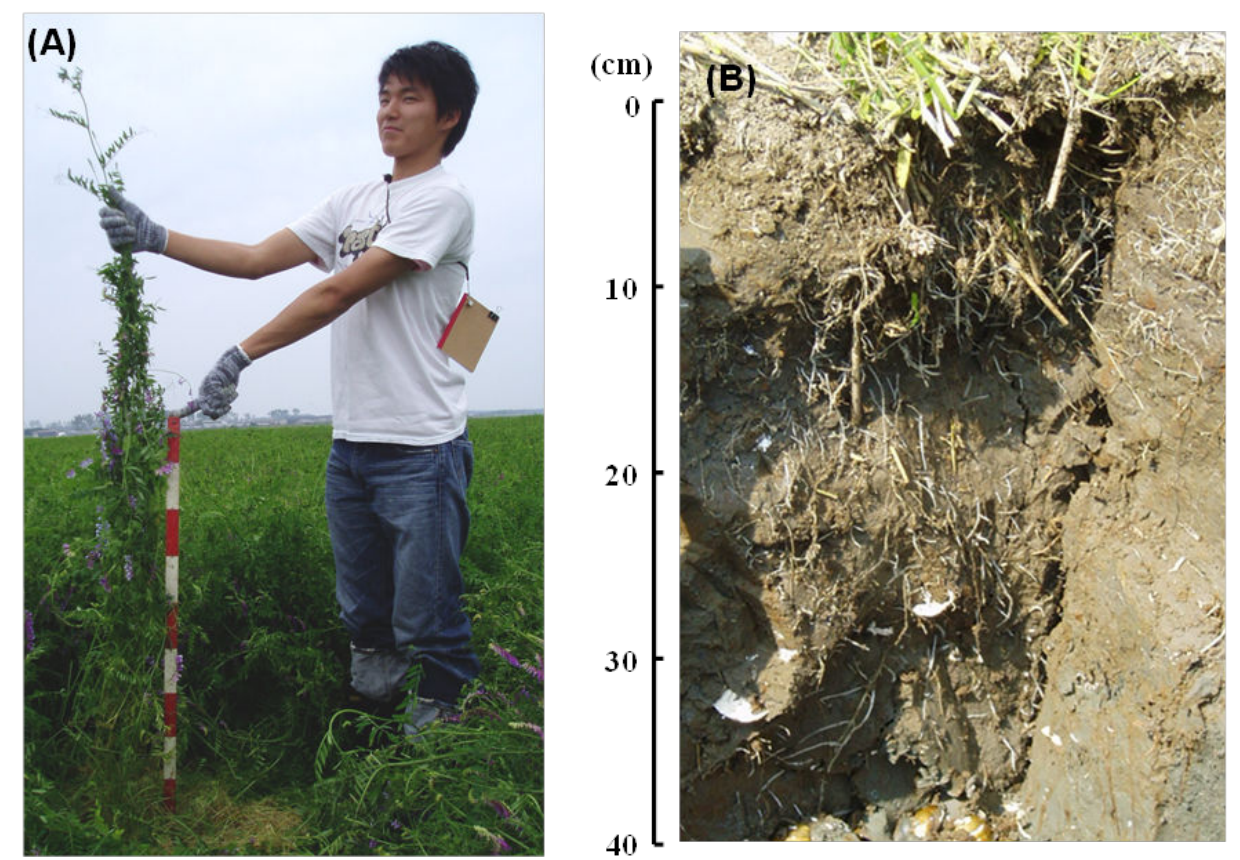

Figure 1. Photos of shoot $(A)$ and root $(B)$ of hairy vetch planted in a upland field converted from paddy field in Akita, Japan. 


\section{Nitrogen utilization of hairy vetch}

Hairy vetch absorbs and utilizes soil nitrogen mainly in the forms of $\mathrm{NH}_{4}{ }^{+}$and $\mathrm{NO}_{3}{ }^{-}$by the roots, and can fix atmospheric nitrogen by the root nodule that is a symbiotic organ with Rhizobium leguminosarum bv. viciae (Fig. 2). Hairy vetch planted in a field can accumulate 100 200 kg nitrogen ha ${ }^{-1}$ year-1 in the plant. The accumulated nitrogen consists of about $90 \%$ of nitrogen fixation by the nodules and about $10 \%$ of absorbed soil nitrogen by the roots estimated from the results of ${ }^{15} \mathrm{~N}$ natural abundance technique. The nitrogen concentration of the organs is $3 \sim 4 \%$ with CN ratio about $10-12$, and total dry matter ranges $200-500 \mathrm{~g} \mathrm{~m}^{-2}$ under field conditions in Japan.

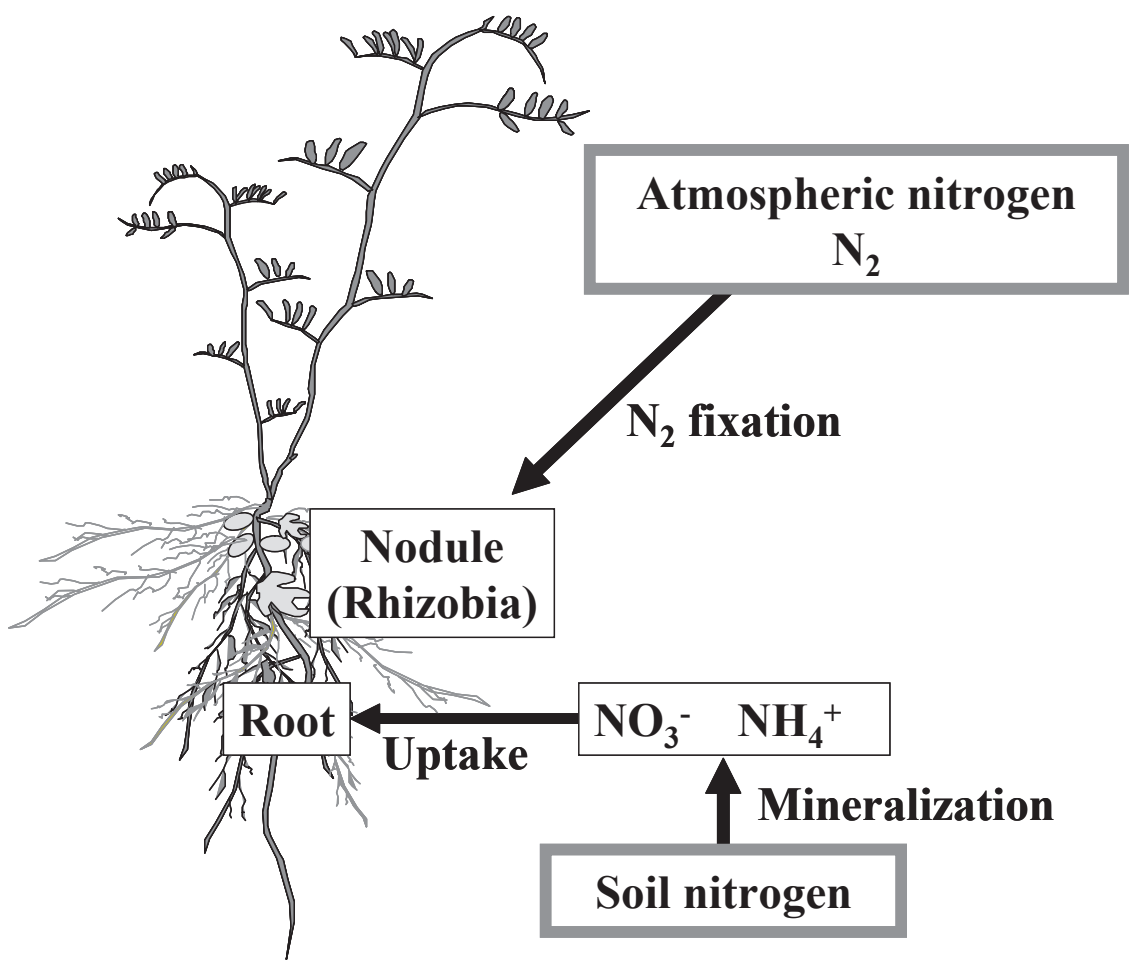

Figure 2. Nitrogen flow and utilization of a legume plants (Hairy vetch).

In early growth stage, hairy vetch plants sometimes show very poor plant growth and exhibit nutritional disorder that the leaves and stems turn to red color. From the results we investigated, the poor plant growth and the nutritional disorder is caused by nitrogen deficiency. Most of the soil nitrogen exists as organic matter, and the soil nitrogen is mineralized to inorganic nitrogen $\left(\mathrm{NH}_{4}{ }^{+}\right.$and $\left.\mathrm{NO}_{3}^{-}\right)$by microorganisms. When temperature is low in autumn, the rate of the soil nitrogen mineralization becomes slow because of low activity of the 
microorganisms in the soil. For that reason, hairy vetch cannot easily utilize soil nitrogen under low temperature conditions. On the other hand, it is considered that nitrogen deficiency is related to the poor nodule formation and low nitrogen fixation activity of the rhizobia in the nodules. It is assumed that there is no rhizobia compatible with hairy vetch in the soil or some indigenous rhizobia show low nitrogen fixing activity under low temperature conditions in northeast area of Japan.

\section{Isolation of a superior hairy vetch rhizobium}

Rhizobium is a genus of Gram-negative soil bacteria and universally survives in a soil. Rhizobium colonizes in the leguminous plant cells within root nodules, and fixes atmospheric dinitrogen $\left(\mathrm{N}_{2}\right)$ to ammonia. Rhizobium provides ammonia as nitrogen source to the host plant, and the host plant provides the rhizobium (bacteroid) organic compounds made by photosynthesis. There is strong host specificity in the symbiosis between rhizobia and legumes.

Hairy vetch establishes symbiosis with Rhizobium leguminosarum bv. viciae and conducts $\mathrm{N}_{2}$ fixation by the nodules. The physiological and genetic diversity of rhizobium is very complicated in the soil [14]. If hairy vetch is infected by a rhizobium that has low affinity for hairy vetch or has low $\mathrm{N}_{2}$ fixation activity, the host plant hairy vetch shows very poor plant growth. So, for good hairy vetch growth it is important to isolate a superior hairy vetch rhizobium and inoculate to the hairy vetch with a superior rhizobium.

Several hairy vetch rhizobium had been isolated from a heavy soil of the upland field converted from a paddy field in Hachirougata polder, Akita Japan. A superior hairy vetch rhizobium was obtained from the isolates and named Y629. The superior hairy vetch rhizobium Y629 was identified Rhizobium leguminosarum bv. viciae by 16S-rRNA gene analysis.

\section{Effect of inoculation of Y629 on hairy vetch growth}

Seeds of hairy vetch were sown in vermiculite medium supplied with nitrogen free culture solution with inoculation of Y629 or indigenous rhizobia. The hairy vetch plants were grown in a growth chamber with high temperature treatment (day: $22^{\circ} \mathrm{C}-12 \mathrm{~h}$, night: $18^{\circ} \mathrm{C}-12 \mathrm{~h}$ ) or low temperature treatment $\left(\right.$ day; $15^{\circ} \mathrm{C}-12 \mathrm{~h}$, night; $7^{\circ} \mathrm{C}-12 \mathrm{~h}$ ).

Hairy vetch plants with inoculation of Y629 normally grew, whereas the plants with inoculation of indigenous rhizobia appeared nutritional disorder irrespective of temperature with poor plant growth (Fig. 3). In high temperature treatment, the nodule number with inoculation of Y629 was fewer than that with inoculation of indigenous rhizobia. However, the nitrogen fixation activity (ARA) per plant with inoculation of Y629 was about two times higher than that with inoculation of indigenous rhizobia. The nitrogen fixation activity with inoculation of Y629 was high even in low temperature condition. These results indicate that the superior hairy vetch rhizobium Y629 shows high nitrogen fixation activity, and Y629 is considered to have low temperature tolerance in a symbiotic state. 


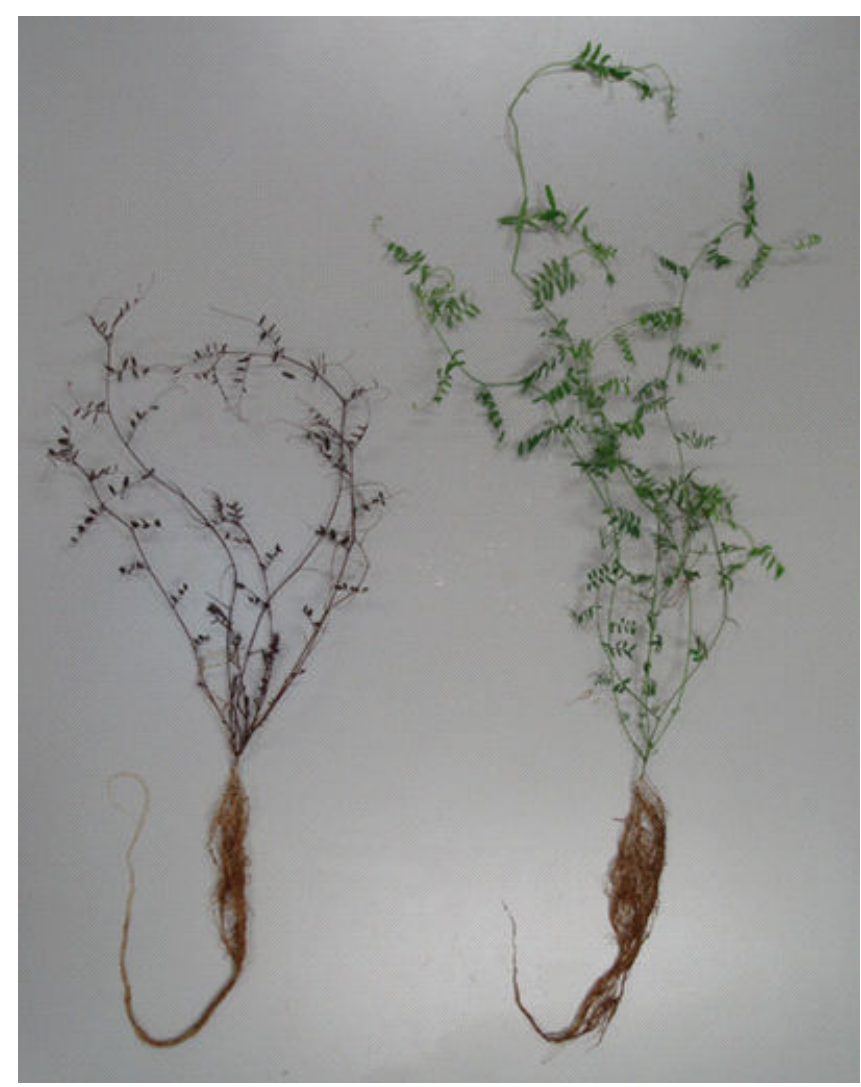

\section{Inoculated with indigenous rhizobia}

Figure 3. Hairy vetch inoculated with Y629 or indigenous rhizobia at high temperature treatment (Day: $22^{\circ} \mathrm{C} 12 \mathrm{~h}$, night: $\left.18^{\circ} \mathrm{C} 12 \mathrm{~h}\right)$.

The nodulation was observed in all the plants, but some nodules with inoculation of indigenous rhizobia showed dark greenish color inside. It has been known that leghemoglobin, a red hemeprotein specifically accumulated in nodules, is an important role in nitrogen fixation in which protects nitrogenase from inactivation by molecular oxygen $\left(\mathrm{O}_{2}\right)$ [15]. The concentration of leghemoglobin in the nodule is an indicator of nitrogen fixation activity. The section of all the nodules inoculated with Y629 showed red color, which is considered as the accumulation of normal leghemoglobin in the infected region of the nodules. However, some nodules inoculated with indigenous rhizobia exhibited dark color, and those sections showing dark greenish color in the infected region of the nodules which is derived from the decomposition product of leghemoglobin (Fig. 4). The nodules showed dark color might have low or no nitrogen fixation activity. This phenomenon is considered to be an early senescence of nodules 
caused by the end of symbiosis. It is assumed that rhizobium harbored in the dark color nodules have low affinity for the host plant. It is interesting to note that some rhizobium can infect and form a nodule with host plant, but cannot maintain symbiosis with their host plants.
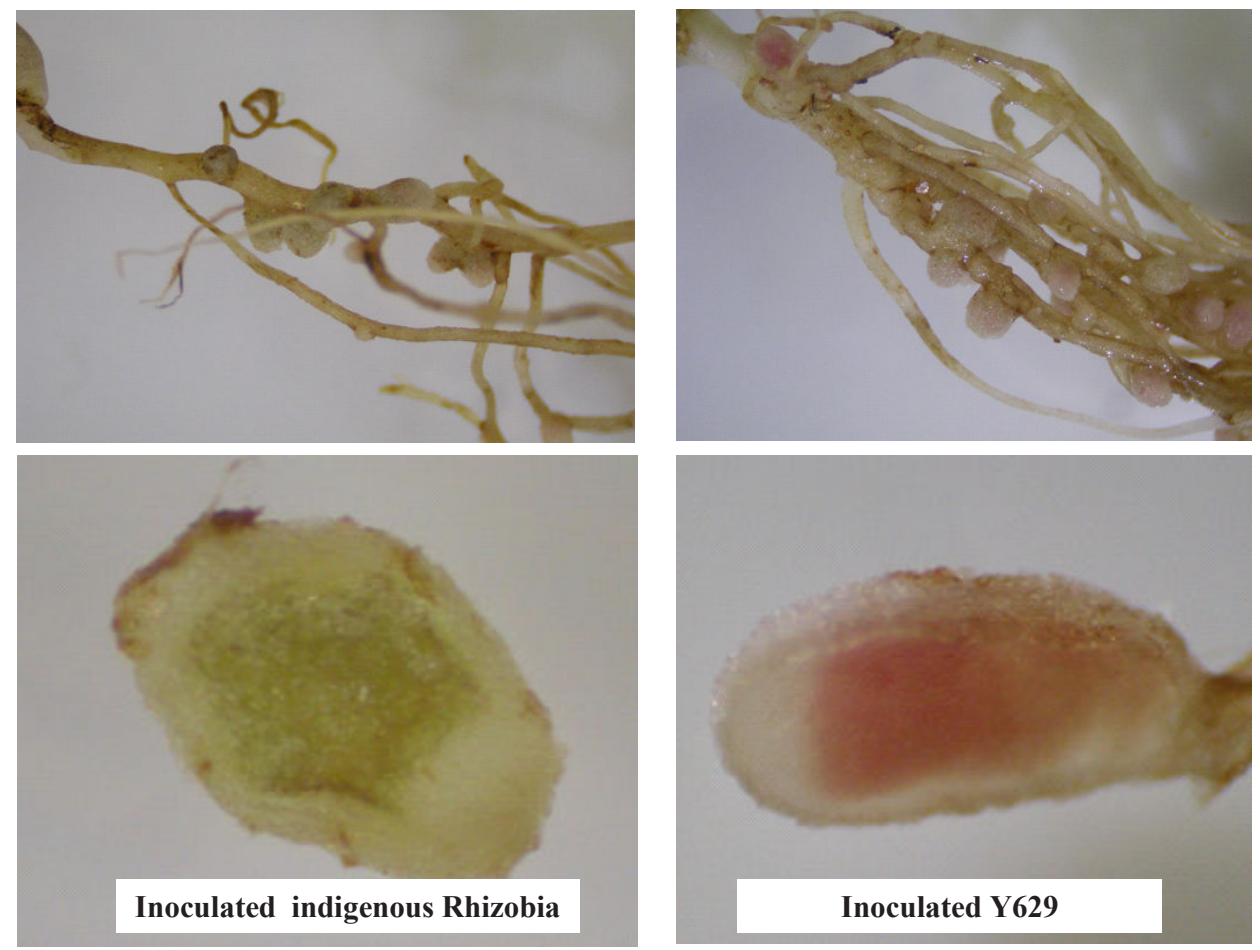

Figure 4. Nodulation and section of nodule of hairy vetch inoculated with Y629 or indigenous rhizobia at high temperature treatment (Day: $22^{\circ} \mathrm{C} 12 \mathrm{~h}$, night: $18^{\circ} \mathrm{C} 12 \mathrm{~h}$ )

\section{Effect of inoculation of Y629 in a field}

An upland field converted from a paddy field in Hachirougata polder, Japan was used for this field experiment. The soil type is heavy clay soil and $\mathrm{pH}$ is 6.5. There is no hairy vetch planting history in the field. Seeds of hairy vetch were sown with or without inoculation of Y629 in early autumn. Rhizobium Y629 was cultured in YM broth at $30{ }^{\circ} \mathrm{C}$ for 3 days. The culture solution was mixed with vermiculite and peat-moss, and then the seeds of hairy vetch were coated by Y629 mixture. The sowing density was $30 \mathrm{~kg} \mathrm{ha}^{-1}$ that is about 200 seeds $\mathrm{m}^{-2}$.

In the field experiment, there was no outstanding effect of Y629 inoculation on the hairy vetch growth before winter. In early spring, the stem length with inoculation of Y629 was as long as that without inoculation. However, about $10 \%$ of the hairy vetch showed nutritional disorder 
in the non-inoculation treatment. It is supposed that the hairy vetch inoculated with Y629 was avoided nitrogen deficiency according to high nitrogen fixation activity by the nodules infected with Y629. In non-inoculation treatment, some hairy vetch plants were infected with indigenous rhizobia, which might have low nitrogen fixation activity or low affinity for the host plant.

The stem length of the plants inoculated with Y629 was slightly higher than those without inoculation in early summer. The dry weight of the shoots with inoculation of Y629 was significantly high compared with non-inoculation treatment. It is confirmed that the hairy vetch growth is promoted by high nitrogen fixation activity by the nodules infected with Y629 under field conditions.

There are many kinds of rhizobia which can establish symbiosis with hairy vetch in the soil of the experimental field. The infection ratio of Y629 with the inoculation method in this experiment might be below $10 \%$ under the field condition where indigenous hairy vetch rhizobia exist in the soil. It is important that the effect of Y629 inoculation on hairy vetch growth is observed in the field condition even if indigenous rhizobia compatible with hairy vetch exist in the soil (Fig. 5).

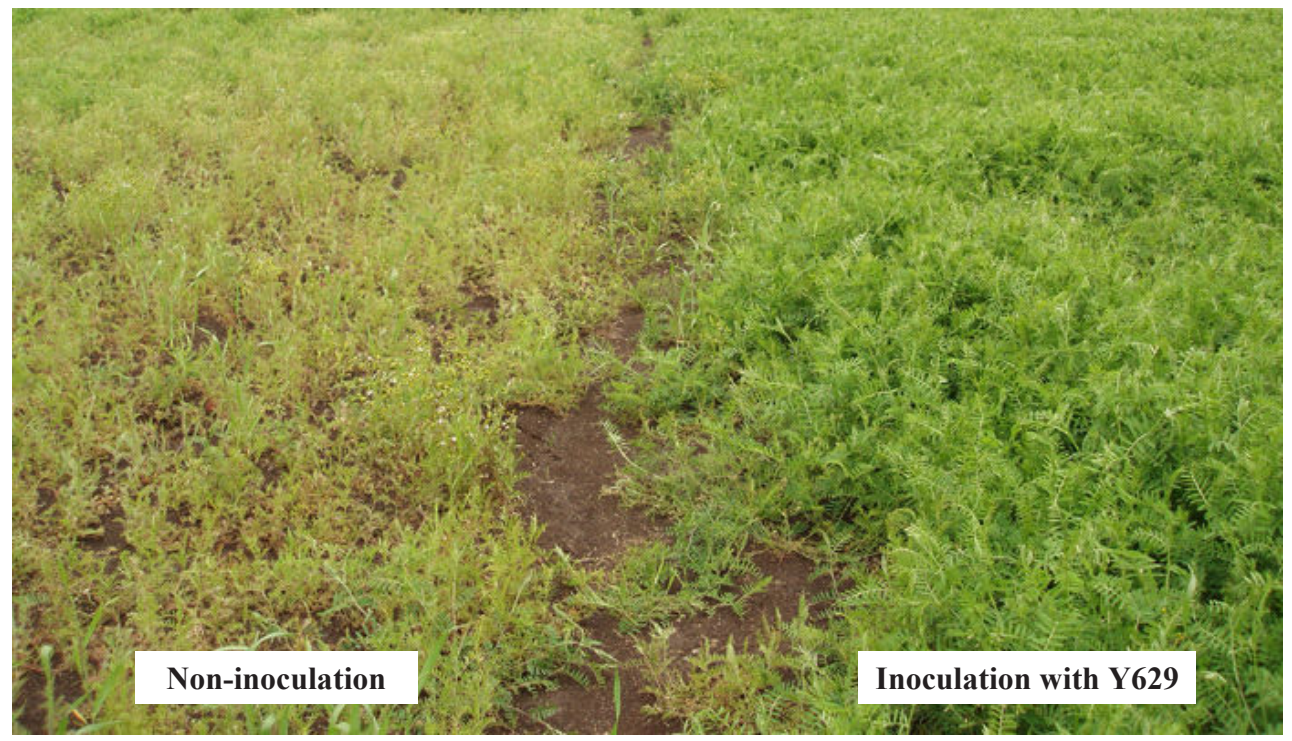

Figure 5. Hairy vetch inoculated with or without Y629 under field condition at 180 days after sowing (15 May 2007$).$

\section{Rhizobium inoculation using micro zeolite powder}

It has been considered that infection ratio of inoculant rhizobium to host leguminous plant is very low in a field condition. In general, commercial rhizobium inoculant product is peat mossbased things, and leguminous crop seeds are usually inoculated mixing with rhizobium 
inoculant prior to sowing. In this study, the infection ratio of $Y 629$ with the seed inoculation might be below $10 \%$ under the field condition where indigenous hairy vetch rhizobia exist in the soil as described above.

On the other hand, it is necessary to inoculate rhizobium just before sowing, because the population of the inoculated rhizobium on the seed decreased immediately due to drought stress [16]. Thus, it is important for increase in infection ratio of inoculated rhizobium to have high rhizobium population on the seed and to maintain high population of rhizobium until sowing.

The micro zeolite powder of about $0.003 \mathrm{~mm}$ in diameter was used for the carrier material of rhizobium inoculant instead of peat moss in the next study. The Y629 YM culture solution at a density of about $10^{8}$ cells $\mathrm{mL}^{-1}$ was mixed with the micro zeolite powder at a rate of 1:1 (volume ratio). Then, $100 \mathrm{~mL}$ of the rhizobium inoculant was mixed with $5 \mathrm{~kg}$ of a hairy vetch seeds, and the inoculated seeds were air dried for 1 hour (Fig. 6). The inoculated seeds were

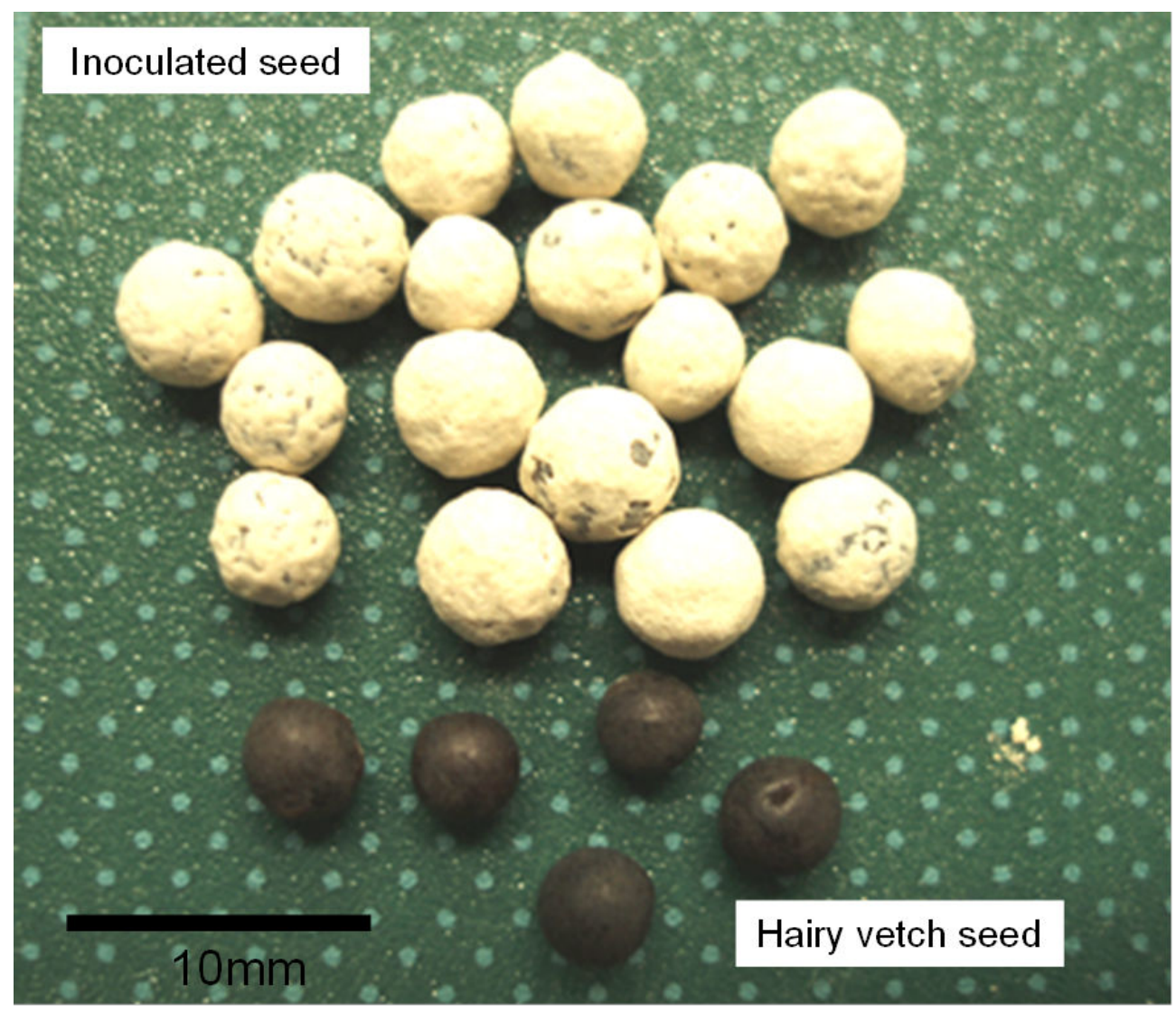

Figure 6. Photo of hairy vetch seeds and seeds inoculated with rhizobium (Y629) using the micro zeolite powder. 
sown to a field with density of $30 \mathrm{~kg} \mathrm{ha}^{-1}$. On the other hand, the inoculated seeds were stored at room temperature with dry condition for 3 month, and then sown to a vermiculite medium filled with nitrogen free culture solution.

The hairy vetch plant was collected from the field at 30 days after sowing, and the rhizobium was isolated from the nodules. The inoculation rhizobium (Y629) was identified by a genotype. The infection ratio of Y629 was about $30 \%$ under the field condition, whereas that with peat moss-based inoculation might be below $10 \%$ under same condition. The rhizobium population on the seeds with the micro zeolite powder inoculant was as high as with peat moss-based inoculant just after the inoculation. The hairy vetch seed takes about ten days for germination under field condition. In the field experiment in this study, the hairy vetch seeds were not conducted soil cover. Therefore, the rhizobium on the seed surface was got drought stress until germination. The rhizobium with the micro zeolite powder might alive on the seed surface in spite of under drought stress, although the reason has not clear yet. The $\mathrm{pH}$ of Y629 culture solution and the micro zeolite powder are about 3 and 10, respectively. It was supposed that the inoculant was neutralized by mixing the rhizobium culture solution and the micro zeolite powder, and the rhizobium was able to maintain population due to improvement of condition to alive on the seed surface. Furthermore, the rhizobium with the micro zeolite powder maintained population enough to form the nodules for 3 month after the inoculation under room temperature with dry condition. The rhizobium inoculant with the micro zeolite powder may be considered to make the rhizobium drought stress tolerant.

\section{Flow inoculation of rhizobium in paddy and upland rotation system}

Hairy vetch has been used for nutrient management as green manure to increase in soil fertility and to amend soil physical properties in paddy field and upland field. The rhizobial seed inoculation is troublesome when the cultivation area is very large and the seed amount is a lot. Furthermore, the host plants may not formed nodules even if the seeds are inoculated with rhizobium, when the method of the inoculation was inappropriate or the climatic conditions are not appropriate for rhizobium survival in the soil. Thus, it is necessary to develop new and easy method for rhizobium inoculation in paddy and upland rotation system.

In a paddy field (1.25 ha), $20 \mathrm{~L}$ of the Y629 YM broth culture solution at a density of about $10^{8}$ cells $\mathrm{mL}^{-1}$ was applied with the irrigation water in summer (Fig. 7). The irrigation water was supplied to the field with flow quantity of about $100 \mathrm{~m}^{3}$ per hour. The application speed of the rhizobium solution was about $5 \mathrm{~L}$ per hour. After the flow inoculation, conventional farm management was carried out until hairy vetch sowing. The hairy vetch seeds were sown without seed inoculation to the field with density of $30 \mathrm{~kg} \mathrm{ha}^{-1}$ at 50 days after the flow inoculation.

The hairy vetch with the flow inoculation formed nodules as well as seed inoculation. The inoculant rhizobium (Y629) population in the soil increased drastically compared with that without flow inoculation treatment. It is considered that the inoculant rhizobium (Y629) could propagate in the soil of the paddy field. The infection ratio of Y629 was about $50 \%$ even if indigenous rhizobia compatible with hairy vetch exist in the soil. In addition, the hairy vetch 

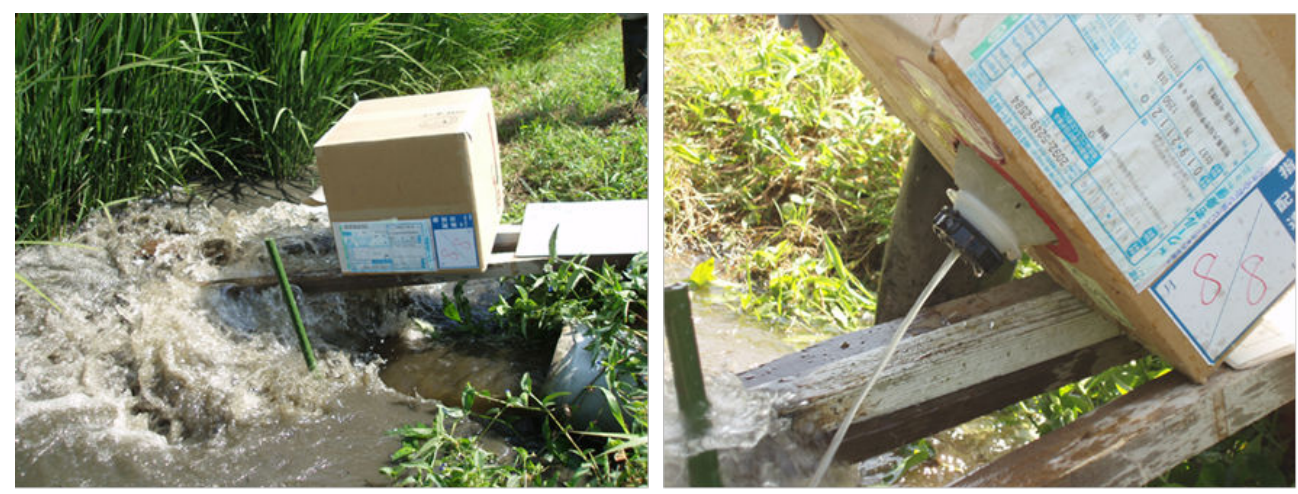

Figure 7. Photos of inoculant setting on the water intake of the paddy field (Left) and applying of rhizobium (Y629) culture solution (Right) with the flow inoculation.

plant growth with the flow inoculation was promoted compared with the seed inoculation treatment. It is supposed that the rhizobium infection to the hairy vetch root with the flow inoculation was faster than that with seed inoculation because the inoculant rhizobium population was very high in the soil surface. Consequently, the flow inoculation of rhizobium was considered to be effective to improve the infection ratio of inoculant rhizobium by simple treatment.

\section{Conclusion}

Hairy vetch is useful for improving soil structure due to their deep root system, increasing soil fertility and weeding for subsequent crops as described above. Hairy vetch is planted in late summer or autumn, and grows until late autumn. The seedling can survive under the snow in winter and then grow vigorously from spring to early summer. If there is no compatible rhizobium strains suitable for hairy vetch in a soil, inoculation with superior rhizobium such as Y629 bring a significant result on promoting hairy vetch growth. The seed inoculation of rhizobium Y629 using the micro zeolite powder is able to keep rhizobium population on the seed surface after the inoculation possibly by protecting from drought stress. The flow inoculation of rhizobium Y629 is simple and effective method to improve the infection ratio of inoculant rhizobium and to promote the hairy vetch growth under field condition.

\section{Author details}

Takashi Sato

Faculty of Bioresource Sciences Akita Prefectural University, Kaidobata-Nishi, ShimoshinjoNakano, Akita, Japan 


\section{References}

[1] Cherr C. M., Scholberg J. M. S., McSorley R. Green Manure Approaches to Crop Production: A Synthesis. Agron. J., 2006; 98, 302-319.

[2] Mappaona, Yashida S., Kitou M. Yield Respone of Cabbage to Several Tropical Green Manure Legumes Incorporated into Soil. Soil Sci. Plant Nutr., 1994; 40, 415-424.

[3] Badaruddin M., Meyer D. W. Green-Manure Legume Effects on Soil Nitrogen, Grain Yield, and Nitrogen Nutrition of Wheat. Crop Sci., 1990; 30, 819-825

[4] Biederbeck V.O., Bouman O.T., Looman J., Slinkard A.E., Bailey L.D., Rice W.A., Janzen, H.H. Productivity of four annual legumes as green manure in dryland cropping systems. Agron. J., 1993; 85, 1035-1043.

[5] Ross S.M., King J.R., Izaurralde R.C. O’Donovan J.T. Weed suppression by seven clover species. Agron. J., 2001; 93, 820-827.

[6] Karpenstein-Machan M., Stuelpnagel, R. Biomass yield and nitrogen fixation of legumes monocropped and intercropped with rye and rotation effects on a subsequent maize crop. Plant Soil, 2000; 218, 215-232.

[7] Choi B., Daimon, H. Effect of hairy vetch incorporated as green manure on growth and N uptake of sorghum crop. Plant Prod. Sci., 2008; 11, 211-216.

[8] Kouyate Z., Franzluebbers K., Juo A.S.R., Hossner, L.R. Tillage, crop residue, legume rotation, and green manure effects on sorghum and millet yields in the semiarid tropics of Mali. Plant Soil, 2000; 225:141-151.

[9] Ladha J.K., Dawe D., Ventura T.S., Singh U., Ventura W., Watanabe, I. Long-term effects of urea and green manure on rice yields and nitrogen balance. Soil Sci. Soc. Am. J., 2000; 64, 1993-2000.

[10] Carsky R.J., Oyewole B., Tian,G. Integrated soil management for the savanna zone ofWest Africa: Legume rotation and fertilizer N. Nutr. Cycling Agroecosyst, 1999; 55, 95-105.

[11] Steinmaier N., Ngoliya A. Potential of pasture legumes in low-external-input and sustainable agriculture (LEISA): I. Results from green manure research in Luapula Province, Zambia. Exp. Agric., 2001; 37, 297-307.

[12] Yoshioka K., Maruyama, Y. Characterization and symbiotic nitrogen fixation of rhizobium that nodulates Chinese milk vetch (Astragalus sinicua, L.). Soil. Soil Sci. Plant Nutr., 1990; 36, 83-90.

[13] Kim S.Y., Oh S.H., Hwang W.H., Choi K.J., Oh, B.G. Optimum Soil Incorporation Time of Chinese MilkVetch (Astragalus sinicus L) for its Natural Re-seed-ing and Green Manuring of Rice in GyeongnamProvince, Korea. J. Crop Sci. Biotech., 2008; 11, 193-198. 
[14] Palmer K. M., J. Young, P. W. Higher Diversity of Rhizobium leguminosarum biovar viciae populations in arable soils than in grass soils, Appl. Environ. Microbiol., 2000; $66,2445-2450$

[15] Appleby C.A. Leghemoglobin and Rhizobium Respiration. Annu. Rev. Plant Physiol., 1984; 35, 443-478. Varia. Soil Sci. Plant Nutr. 55, 235-242.

[16] Rosalind D., Rodney J. R., Ivan R. K. Legume seed inoculation technology - a review. Soil Biology and Biochemistry, 2004; 36, 1275-1288. 